\title{
Explosive volcanism on Venus: Transient volcanic explosions as a mechanism for localized pyroclast dispersal
}

\author{
Sarah A. Fagents ${ }^{1}$ and Lionel Wilson \\ Environmental Science Division, Institute of Environmental and Biological Sciences, Lancaster University, Lancaster, \\ England
}

\begin{abstract}
It is proposed that transient volcanic explosions of the vulcanian type may provide a mechanism for the generation and dispersal of pyroclastic material on Venus. The influence of the Venusian high atmospheric pressure environment implies that continuous discharge plinian eruptive activity is relatively uncommon: the tendency for suppression of exsolution and expansion of magmatic gases favors effusive eruptions. However, it may be possible for explosive activity to occur, in a fashion analogous to vulcanian eruptions on Earth, as a result of the accumulation of hot, pressurized gas under a coherent rock "lid". The explosion may be initiated by the failure of this retaining caprock, causing the catastrophic release of the high-pressure gas, which expands out of the vent driving the fragmented caprock material ahead of it and displacing the surrounding atmosphere. On Earth the driving gas may originate either from vaporization of groundwater or from degassing of a stalled magma body in the near-surface crust, whereas on Venus, where the presence of crustal stores of volatile compounds is uncertain, the latter option only is favored: prolonged degassing may lead to an accumulation of gas sufficient to initiate an explosion. This paper presents the results of a numerical model describing the explosion process under boundary conditions representing the Venusian physical environment. This involves treatments of the acceleration of the driving gas, caprock and displaced atmospheric gas out of the vent and the subsequent motions and aerodynamic interactions between the atmosphere and the ejected blocks of fragmented caprock. In this way, predictions of the eruption velocities and of the resulting distribution of (large) solid ejecta can be obtained for likely conditions on Venus. Deposits of large blocky debris are predicted to range up to a maximum distance of the order of $1 \mathrm{~km}$ from the vent on Venus, compared with distances of several kilometers commonly attained by ejecta from transient explosions on Earth. More typical blocky deposits may extend for only a few hundred meters, which implies that they would not be detected in the Magellan radar data. However, the possible presence of associated pyroclastic flow and fine-grained ashfall deposits may constitute aids to the identification of sites of vulcanian eruptions on Venus.
\end{abstract}

\section{Introduction}

The very high atmospheric pressure on Venus (ranging from $\sim 10 \mathrm{MPa}$ to $\sim 5 \mathrm{MPa}$ over the $\sim 10 \mathrm{~km}$ range of planetary elevation) will tend to suppress, or at least reduce, the exsolution and expansion of volatiles contained in ascending magmas [Wood, 1979; Wilson and Head, 1983; Head and Wilson, 1986]. Uncommonly high (by terrestrial standards) total magmatic volatile contents are required for subsurface magma fragmentation (and hence the initiation of explosive activity in which a steady discharge of gas and pyroclasts takes place) to occur at all [Garvin et al., 1982; Head and Wilson, 1986]. It is by no means clear that these volatile contents are achievable in magmas on Venus. Furthermore, exsolved volatile contents in excess of several weight percent, together with favorable combinations of high vent altitude and eruption temperature, are necessary for eruptions feeding high, convecting eruption clouds to be maintained. Otherwise the collapse of the eruption column and

\footnotetext{
${ }^{1}$ Now at Center for Earth and Planetary Studies, National Air and Space Museum, Smithsonian Institution, Washington, D.C.

Copyright 1995 by the American Geophysical Union.

Paper number 95JE03202.

0148-0227/95/95JE-03202\$05.00
}

the formation of pyroclastic flows is more likely [Sugita and Matsui, 1993; Thornhill, 1993]. It may be expected therefore that steady explosive (plinian or Hawaiian) activity on Venus is relatively uncommon, with effusive activity dominating. Indeed, analyses of the huge amount of high-resolution radar data returned by the Magellan mission to Venus have demonstrated the widespread occurrence of vast volcanic plains and immense lava flows [e.g., Head et al., 1991], with relatively few indications of pyroclastic activity [Head et al., 1991; Guest et al., 1992; Ivanov, 1992; Moore et al., 1992; Wenrich and Greeley, 1992]. Nevertheless, intermittent, transient explosive eruptions are possible at quite modest magmatic volatile contents on Venus if gas concentration occurs in a slowly ascending or stationary intruded magma. The result may be Strombolian activity in lowviscosity, mafic magmas [Garvin et al., 1982] or vulcanian activity in more viscous melts [Fagents, 1994].

Fagents and Wilson [1993] developed a model for transient vulcanian explosive eruptions on Earth based on the scenario in which magma intrudes close to the surface of the planet but fails to erupt (most likely because the rise rate is sufficiently slow that excessive cooling intervenes). Exsolving volatiles may accumulate at the top of such a magma column, possibly as a foam but later, if the foam collapses [Jaupart and Vergniolle, 1989], as a gas pocket. This magmatic gas may effectively be trapped beneath a rigid "lid" if the pathway to the surface is sealed 
(possibly by magma invading any near-surface fractures). Alternatively, if potentially volatile compounds exist within the country rocks, these may be evaporated and trapped as highpressure gases if their path is not connected efficiently to the surface. The failure of part of the lid overlying an accumulation of high-pressure gases leads to the expansion of locally released gases and the acceleration of the overlying rocks. Furthermore, local decompression leads to the propagation of an expansion wave into the surroundings, and this can trigger failure of more of the lid, leading quickly to the catastrophic disruption of all of the pressurized region in a vulcanian style explosion [Wilson, 1980]. The Fagents and Wilson [1993] model incorporates a detailed treatment of the mutual aerodynamic interactions between volcanic ejecta and the gas flow field around the eruptive site and thus represents a significant improvement over previous efforts to model the dispersal of coarse volcanic material. Analyses of a number of terrestrial eruptions have shown that, by comparing computed travel distances of large clasts ejected in such explosions with their observed positions in the field, it is possible to constrain the ranges of initial conditions that would explain the observed dispersal of ejecta [Fagents and Wilson, 1993; Fagents, 1994]. Geologically plausible values of these parameters (excess gas pressure, gas mass fraction, and source region radius) are obtained. Having tested this model with terrestrial case studies, it now seems appropriate, in view of the questions raised by Magellan about Venus still being volcanically active, to employ the model to predict the extents of eruptive deposits from transient volcanic explosions on Venus, given plausible preeruption conditions.

A number of candidate sites for explosive volcanism have been identified on Venus [e.g., Head et al., 1991, 1992; Ivanov, 1992; Moore et al., 1992; Wenrich and Greeley, 1992; Campbell, 1994; Campbell and Rogers; 1994], with evidence for quite localized activity in some locations [e.g., Bulmer, 1994]. The nature and modes of formation of these deposits are poorly understood. The study presented in this paper represents an investigation into how the products of one well-known style of explosive eruption would be manifested in the Venusian environment. Initially, we review the reasons for anticipating that vulcanian-type explosive eruptions are possible on Venus and give details of how the theoretical model of Fagents and Wilson [1993] can be used to describe this explosion process under Venusian physical environmental conditions. We then present the predictions that can be made about the dimensions and grainsize characteristics of the deposits that might be expected to be produced.

\section{Background}

\section{Volcanism on Venus}

The analysis of Magellan synthetic aperture radar (SAR) images of Venus has revealed a startling array of volcanic features, including shield volcanoes and lava flows on many scales, the morphologies of which are consistent with a basaltic composition [Head et al., 1991]. Venera Lander geochemical data also indicate possible tholeiitic or alkali basalt surface rock compositions [Surkov et al., 1984, 1987]. There is some evidence that more evolved magmas exist on Venus: Venera 8 gamma ray spectrometer data suggest an intermediate to silicic composition [Surkov et al., 1976, 1977; Nikolaeva, 1990] at one site. Furthermore, the morphologies of some steep-sided, flat-topped "pancake" domes observed in plains areas of Venus are reminiscent (albeit on a larger scale) of rhyolite-dacite domes on Earth [Head et al., 1991, 1992; Guest et al., 1992; Pavri et al.,
1992]. Whether this high-viscosity morphology is indicative of a more silicic magma, or is simply a cooling-induced feature, or the effect of a highly inflated bubble-rich magma, remains open to debate [McKenzie et al., 1992; Pavri et al., 1992; Sakimoto and Zuber, 1993].

Consideration of volatile solubilities with respect to the high atmospheric pressure on Venus causes doubts as to whether steady explosive activity can occur at all. For typical magmatic volatile contents, the high pressure will act to inhibit or at least reduce the exsolution and expansion of magmatic gases [Wood, 1979; Garvin et al., 1982; Wilson and Head, 1983; Head and Wilson, 1986]. In the shallow lithosphere, lithostatic pressures are greater than on the Earth as a result of the high atmospheric surface pressure. As a result, the pressures at which magma fragmentation takes place (when the magmatic gas bubble volume fraction exceeds some critical value of $\sim 0.75$ [Sparks, 1978]) are always reached at shallower depths on Venus [Garvin et al., 1982; Head and Wilson, 1986] and much larger volatile contents are required if magma fragmentation is to take place at all. Table 1 gives the minimum total $\mathrm{H}_{2} \mathrm{O}$ and $\mathrm{CO}_{2}$ contents required for disruption of a basaltic magma at various vent altitudes. For rhyolitic magmas, Head and Wilson [1986] show that exsolved volatile contents of several weight percent are needed for plinian eruption columns to form. Clearly, the minimum volatile contents required for the disruption of Venusian magmas (i.e., to produce continuous explosive eruptions) lie above or at the upper end of the range of typical magmatic volatile contents of terrestrial magmas [Basaltic Volcanism Study Project, 1981].

Even if a magma on Venus contains sufficient volatiles for the gas to be released by fragmentation, the high external pressure will also reduce the amount of gas expansion. This reduces the energy available to drive the eruption, which is a function of the ratio of the initial (preexpansion) and final (atmospheric) gas pressures, relative to that on Earth. The velocity reached by the erupting fluid on reaching the surface will therefore be rather modest compared with terrestrial conditions. Thornhill [1993] shows that steady explosive plinian activity, forming a high convecting eruption cloud, can only be sustained for unlikely combinations of high volatile contents, high vent altitudes and high eruption temperatures; fountain-fed pyroclastic flows are more likely to occur in an explosive scenario. It seems likely that steady explosive ashfall activity, while not necessarily absent (tentative identification has been made of plinian ashfall deposits in Bell Regio [Barsukov et al., 1986; Campbell and Rogers, 1994] and Guinevere Planitia [Head et al., 1991]), is rare on Venus.

However, transient activity may be rather more common. Garvin et al. [1982] argued that Strombolian activity is possible in low-viscosity Venusian basalts if they ascend through the crust sufficiently slowly. The low rise speed allows time for bubble growth by gas diffusion; then, as the buoyancy-driven upward acceleration of bubbles becomes more important, there are an

Table 1. Minimum Volatile Contents in Weight Percent Required for Magma Fragmentation on Venus

\begin{tabular}{clcc}
\hline & \multicolumn{4}{c}{ Vent Altitude in km above mpr } \\
Volatile Species & $\mathbf{0}$ & $\mathbf{5}$ & $\mathbf{1 0}$ \\
\hline & & 2.1 & 1.5 \\
$\mathrm{H}_{2} \mathrm{O}$ & 2.8 & 3.9 & 2.8 \\
$\mathrm{CO}_{2}$ & 5.3 & 3.9 & \\
\hline
\end{tabular}


increasing number of coalescence events and further growth by decompression. The end result is large, rapidly rising bubbles representing significant local volatile enrichment, which ultimately burst through the surface of the melt, disrupting it into a fine spray of pyroclasts [Blackburn et al., 1976].

In a similar fashion, vulcanian activity can occur on Venus as a result of gas exsolution and accumulation under a retaining lid where a magma is rising slowly or has stalled near to the surface. Given sufficient time for gas to accumulate, even low magmatic volatile contents (of any species) can produce a significant concentration beneath the caprock. Whereas the dense Venusian atmosphere will rapidly suppress the flight of the relatively finergrained Strombolian ejecta, leading to ranges of only a few meters [Garvin et al., 1982], the larger pieces of fragmented caprock ejected during vulcanian events, by virtue of their greater inertia, will be able to attain significantly greater distances.

\section{Transient Vulcanian Explosions}

Vulcanian eruptions are defined as discrete, intermittent volcanic explosions separated by intervals of minutes to hours or days [Wilson, 1980] and on Earth are typically associated with intermediate composition stratovolcanoes. Dense slugs of gas and solid material are ejected at velocities that may be supersonic relative to the speed of sound in the surrounding atmosphere (as evidenced by the observation of shock waves [Steinberg and Steinberg, 1975; Nairn, 1976; Livshitts and Bolkhovitinov, 1977]), with pyroclastic ejecta usually consisting of $\geq 50 \mathrm{wt} \%$ nonjuvenile material. A proportion of the ejected material consists of large lithic and juvenile blocks projected on near-ballistic paths. Finer material is entrained into a convecting eruption cloud, which typically reaches heights on Earth of $<5$ to $20 \mathrm{~km}$ [Cas and Wright, 1988] in single isolated events. On Earth, small-volume pyroclastic flows are commonly, but not necessarily, associated with vulcanian eruptions, as a result of rapid fall back of ejecta onto the summit area of the volcano. However, the observed run-out distances and inferred flow velocities are relatively small, which is consistent with both the limited volumes of material emitted and the low degree of fluidization occurring as a result of the high proportion of nonjuvenile (and hence cooler) rock.

The earliest work on modeling terrestrial vulcanian eruptions used the so-called modified Bernoulli equation (MBE) [Matuzawa, 1933] or the gun-barrel equation (GBE) [Minakami, 1950; Decker and Hadikusumo, 1961] to give a relationship between the velocity with which clasts were expelled from an explosion site and the pressure in the trapped gas responsible for the explosion. No very accurate estimates of eruption velocity have been obtained from direct observations of vulcanian eruptions on Earth. Estimates derived from photographic methods (in the few cases where images with high enough spatial resolution have been obtained: Chouet et al. [1974], Nairn and Self [1978], Steinberg and Babenko [1978], and Ripepe et al. [1993]) suffer from inadequate framing rates to follow the rapid accelerations and decelerations at the onset of the explosions. It is thus very difficult to obtain the peak velocity (after expansion out of the vent) that is required to be linked with the excess pressure in the vent. In early studies, initial clast velocities, and hence pressures, were inferred from the observed ranges of clasts using the classical ballistic equation which neglects atmospheric drag forces [Gorshkov, 1959; Decker and Hadikusumo, 1961; Gorshkov and Bogoyavlenskaya, 1965; Hédervári, 1968; Steinberg, 1977; Self et al., 1980]. Attempts at accounting for the atmospheric proper- ties saw the introduction of an expression for drag resistance, which is a function of velocity, atmospheric density, and block radius. Fudali and Melson [1972] and Steinberg and Steinberg [1975] used a constant drag coefficient, which is not in general an adequate assumption: given that the drag coefficient is a function of the Reynolds number [Hoerner, 1965], the drag force will vary as gas decompression progresses and therefore as the relative velocity of the clast with respect to the atmosphere varies. Wilson [1972] described a computational scheme that allowed the trajectory of a pyroclast launched from a given point with a chosen velocity vector to be followed by taking detailed account of the variation of aerodynamic drag forces acting on the clast with varying Reynolds and Mach numbers. This was subsequently used to infer the initial velocities of clasts ejected in vulcanian eruptions by Nairn [1976], Steinberg [1977], Steinberg and Babenko [1978], and Self et al. [1980].

The pressures obtained from use of the MBE and GBE were all unexpectedly high (e.g., 360 to $500 \mathrm{MPa}$ for Bezymianny 1955 [Gorshkov, 1959]; 300 to $500 \mathrm{MPa}$ for Bezymianny 1955 and Arenal 1968 [McBirney, 1973]; $490 \mathrm{MPa}$ for Arenal 1968 [Melson and Saenz, 1973]; $200 \mathrm{MPa}$ for Ngauruhoe 1975 [Nairn and Self, 1978]). The overpressure required for failure to occur in a rock is no more than twice its tensile strength [e.g., Tait et al., 1989]. Touloukian et al. [1981] measured tensile strengths of 8.6 \pm 1.4 and $13.8 \pm 2.1 \mathrm{MPa}$ for pristine samples of basalt and granite, respectively; values for sedimentary rocks are lower than those of basalt by a factor of 2 to 3 [Tait et al., 1989]. In volcanic terrains where fractured, scoriaceous, or rubbly overburden is present, tensile strengths are likely to be significantly less than for laboratory specimens. Furthermore, field examination of hot dacitic lava blocks has indicated that their strengths may be low: the blocks were easily shattered by blows from a hammer [Mellors et al., 1988; Sato et al., 1992]. These lower strengths may be attributed to thermal stresses, trapped residual gas or high strain due to the presence of a large proportion of crystals within the viscous melt. It follows that caprock consisting of hot juvenile material may be expected to display similar properties of failure. Thus it may be argued that maximum tensile strengths may be of order $10 \mathrm{MPa}$, leading to a maximum possible excess gas pressure of $\sim 20 \mathrm{MPa}$; this is at least 1 order of magnitude smaller than the pressures calculated from the MBE and GBE.

In a reappraisal of the fluid mechanics of volcanic explosive processes, Wilson [1980] showed that the MBE and GBE are in fact inappropriate for describing any type of eruption and proposed a treatment which took explicit account of the gas expansion during explosions. This analysis was readily shown to lead to lower preeruption pressures [Self et al., 1979]. However, an assumption employed in setting up this model was that clasts were ejected into an atmosphere at rest. Fagents and Wilson [1993] pointed out that the initiation of a transient eruption will cause the atmosphere overlying the vent to be displaced en masse, such that the initial speed of the displaced atmosphere will be essentially the same as that of the ejected caprock. As the caprock ruptures into fragments, individual blocks are launched into atmosphere moving at approximately the same speed. The implication is that initial drag forces acting on the clasts are essentially zero, only becoming significant as the gas velocity decays, a striking contrast to the earlier work in which the gasclast relative velocity (and hence drag force) would have been assumed to be initially very high. Thus the velocity (and therefore initial excess pressure) required for a block to reach a given distance from the vent would have been greatly overestimated. Fagents and Wilson [1993] showed that, with due 
allowance for this effect, preexplosion gas pressures completely compatible with rock tensile strengths were predicted for a number of well-documented eruptions.

Turcotte et al. [1990] employed a treatment of the unsteady flow of a "pseudogas" through an expansion fan to model vulcanian eruptions. However, the assumption of a pseudogas (in this case approximating finely divided magmatic material thermally and physically coupled with the exsolved juvenile phase) is inconsistent with scenarios in which a large proportion of the eruptive products consists of blocky, nonjuvenile material driven ahead of the expanding gas phase. Field observations of deposits produced from transient eruptions in which at least some juvenile gas was involved support the premise that the erupted material is not a homogeneous mixture of gas and fine particulates, but rather a highly nonuniform mixture of gas, juvenile material, and country rock. The model of Turcotte et al. [1990] may therefore be more applicable to transient eruptions in which material is much more finely fragmented, for example, phreatomagmatic events in which a large proportion of the driving volatile is supplied as external water [Sheridan and Wohletz, 1981, 1983; Wohletz, 1983; Wohletz and Sheridan, 1983].

There is still considerable uncertainty as to the origins of the gases involved in most vulcanian explosions on Earth. Fagents [1994] demonstrated that gas mass fractions required for typical vulcanian explosions are greater than magmatic volatile contents, which implies a significant concentration of gas beneath the vent by some means. The buildup of gas pressure responsible for the initiation of a transient explosion may be gradual, as in the case of quiescent degassing of a stationary magma body, or more sudden, as a result of rapid vaporization of groundwater. Gas may be contributed from either source. However, involvement of a large amount of external water ensures greater efficiency of thermal to mechanical energy transfer and a more thoroughly fragmented magma, leading to phreatic or phreatomagmatic eruptions of fine-grained material [Wohletz, 1983], most of which will be incorporated into a convecting eruption cloud. In the case of Venus, we do not anticipate the presence of large amounts of volatiles in the country rocks, and so we infer that the model described by Fagents and Wilson [1993] will be most appropriate for the description of vulcanian eruptions.

\section{The Explosion Model}

It is assumed that pressurized gas (juvenile or meteoric) accumulates beneath a retaining medium, which may consist of a plug of older lava or volcanic debris (if the eruptive center is already established) or simply comprise the preexisting ground surface in the case of a new explosion site (e.g., the initial explosions at Arenal volcano 1968 [Melson and Saenz, 1973] and the Ukinrek Maars 1977 [Kienle et al., 1980]). As the pressure rises, the tensile strength of the caprock may be exceeded, at which point it fails. The pressurized gas is able to expand out of the vent, pushing the caprock ahead of it and displacing the atmosphere around the explosion site.

Consider a region subtending a solid angle $\Omega$ at a point (Figure 1a). Gas at excess pressure $P_{g z}$ and density $\rho_{g z}$ occupies the region out to a distance $r_{1}$. The solid caprock of density $\rho_{s}$ occupies the region from $r_{1}$ to $r_{2}$. After failure of the caprock, the gas expands adiabatically, pushing ahead of it the caprock and displacing the surrounding atmospheric gas. The equation of motion for the caprock plus mass of displaced air is

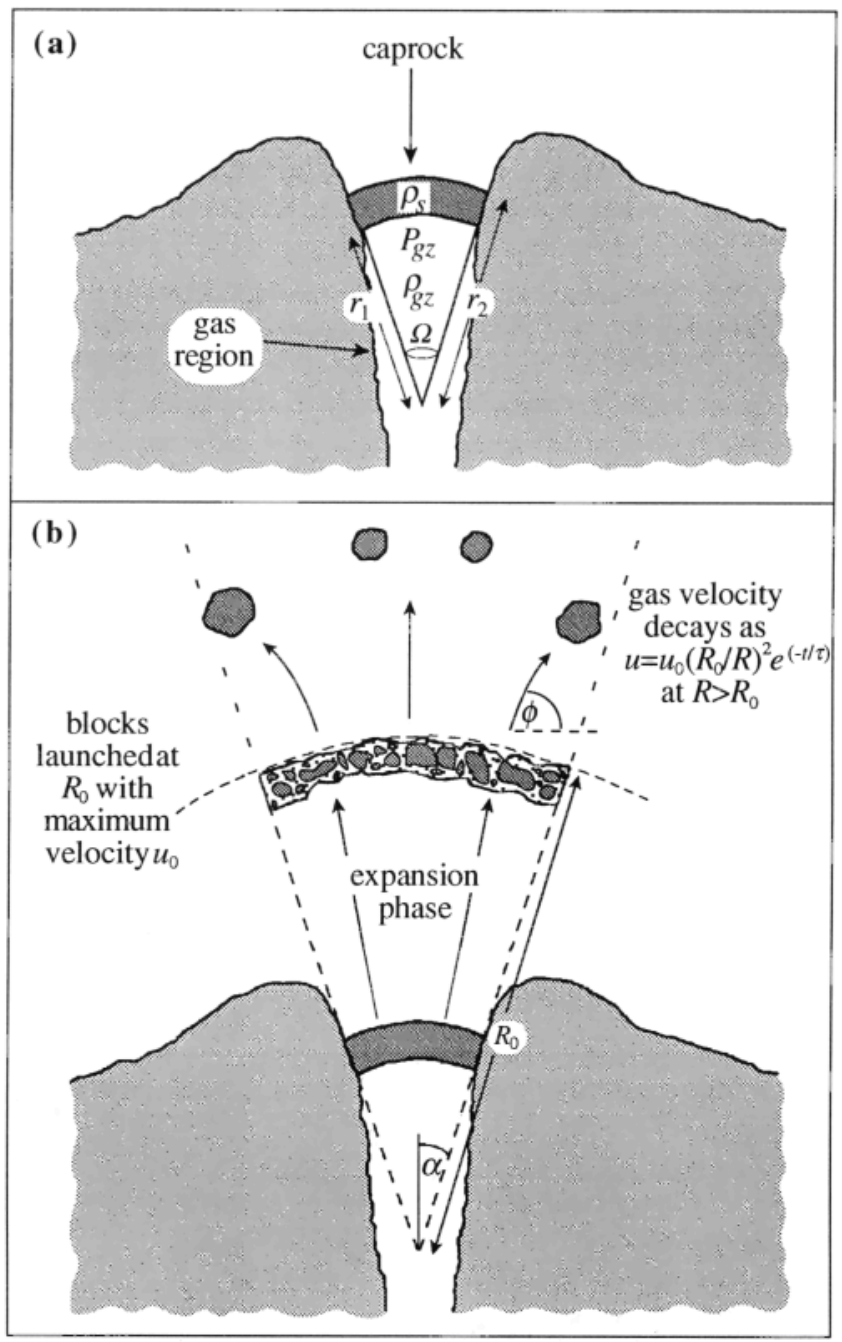

Figure 1. (a) Vent region geometry: gas at excess pressure $\boldsymbol{P}_{g z}$ and density $\rho_{g z}$ occupies a region of radius $r_{1}$ subtending a solid angle $\Omega$. Solid caprock of density $\rho_{s}$ overlies the gas region and extends to a distance $r_{2}$. (b) Diagram showing the initial expansion phase of the gas out of the vent to a distance $R_{0}$ and velocity $u_{0}$, and the subsequent launch of blocks of fragmented caprock into the gas flow field. Modified from Fagents and Wilson [1993].

$$
\left.\frac{d^{2} r}{d t^{2}}=\frac{3 r^{2}\left\{P_{g z}\left(r_{1} / r\right)^{3 \gamma}-P_{a}\right\}}{\left\{\rho_{s}\left(r_{2}{ }^{3}-r_{1}{ }^{3}\right)+\rho_{a}\left[\left(r+r_{21}\right)^{3}-r_{2}{ }^{3}\right]\right.}\right\}
$$

where $P_{a}$ and $\rho_{a}$ are the atmospheric pressure and density, $\gamma$ is the ratio of the specific heats of the trapped gas, and $r_{21}=r_{2}-r_{1}$. Integration of equation (1) yields the maximum velocity of the expanding envelope, $u_{0}$, at which point it is proposed that the caprock makes the transition to a collection of fragmented blocks, which are then launched with this velocity into the moving gas flow field (Figure 1b). The gas velocity, $u$, decays from its maximum at distance $R_{0}$ and time $t_{0}$ such that at any further distance $R$ and subsequent time $t$, we have the relationship

$$
u=u_{0}\left(\frac{R_{0}}{R}\right)^{2} e^{-t / \tau}
$$


This radial variation of $u$ represents the continuity equation for the displaced atmosphere (treated as incompressible). The time constant $\tau$ is given by

$$
\tau=t^{\prime}-t_{0},
$$

where $t^{\prime}$ is the duration of the whole "gas thrust" phase, at the end of which, if convective motion were not to take over, the gas would have decelerated to zero velocity (i.e., after the initial kinetic energy of the gas has been expended). This is found by continuing the integration of equation (1) until the condition $u=0$ is reached. The form of $\tau$ represents an improvement over that given in Fagents and Wilson [1993], in that equation (3) more satisfactorily accounts for the faster anticipated velocity decay on Venus relative to the Earth, which would result from the much lower ratio of vent excess pressure to external atmospheric pressure.

This model allows for lateral expansion of gas above the vent, which is most likely to occur when there is no vent/cone structure to channel the material vertically upwards. Previous models only treated one-dimensional gas expansion, which would lead to the prediction of a greater velocity for a given pressure because none of the energy from the expanding gas would be used in accelerating the erupting material laterally .

The model is implemented in two FORTRAN computer programs: the first describes the initial gas expansion phase of the explosion, to find the launch velocity $u_{0}$, launch position $R_{0}$, and gas velocity decay constant $\tau$ for any chosen combination of initial gas pressure $P_{g z}$, gas mass fraction $n$, and gas region radius $r_{1}$; the second computes the pyroclast trajectory and landing position subject to the atmospheric motion given the parameters $u_{0}$, $R_{0}, \tau$, and the clast density and radius.

\section{Application of Model to Venus}

In order to predict the likely ranges of ejecta in vulcanian explosions on Venus it is necessary to choose plausible ranges of values for the parameters controlling the explosion process: the initial gas pressure $P_{g z}$, the gas mass fraction $n$ and the gas region radius $r_{1}$; and also for the properties of the atmosphere through which the ejected pyroclasts travel. We address these factors in turn.

\section{Initial Gas Pressure}

It seems likely, given that the ranges of compositions of terrestrial and Venusian rocks are taken to be broadly similar, that their tensile strengths will also be similar. It may be argued, however, that the pervasive fracturing of volcanic terrains observed on Venus from Magellan images may cause likely caprock strengths (and hence the corresponding excess pressures which accumulate in trapped gases) to fall in the lower end of the range of expected terrestrial values. However, for the sake of comparison, the entire range of vent pressures expected on the basis of analyses of terrestrial vulcanian explosions, $P_{g z}=0.01$ to $20 \mathrm{MPa}$, has been investigated.

\section{Gas Mass Fraction}

The high abundance of $\mathrm{CO}_{2}$ (and paucity of $\mathrm{H}_{2} \mathrm{O}$ ) in the present-day Venusian atmosphere suggests that $\mathrm{CO}_{2}$ may currently be the main volatile species in magma source regions. However, despite the fact that some geochemical models of Venus call for an extreme $\mathrm{H}_{2} \mathrm{O}$-depleted interior [e.g., Goettel et al., 1981], there appears to be no direct evidence that Venusian magmas do not contain at least some $\mathrm{H}_{2} \mathrm{O}$ [Head and Wilson, 1986]. As an alternative to the driving gases being provided by a magmatic source, the ascending magma may encounter a volatile reservoir contained within the lithosphere. Water and carbon dioxide cannot exist in solid or liquid phases under the present high-temperature conditions on Venus, but thermodynamic calculations show that sulfur, if present, would be stable as a liquid almost anywhere on the Venusian surface or at depths up to several hundred meters [Head and Wilson, 1986]. The possibility of $\mathrm{CO}_{2}$ release by thermal decomposition of carbonate sediments has also been considered [Head and Wilson, 1986]. Although it is not clear that country rock volatiles may be encountered during magma ascent on Venus, there is every reason to believe that at least some magmatic volatiles will commonly be liberated as magmas approach the surface [ Head and Wilson, 1992], thus ensuring that a mechanism for generating volatiles that can accumulate in stalled magma bodies does in fact exist. However, there is no simple way of predicting an upper limit on the gas/caprock mass ratio $(n)$, since it is dependent on many factors: the dimensions of both the caprock and the gas pocket; the source of the gas (magma or country rock); and the residence time of the magma in the near-surface crust. An upper value of $30 \mathrm{wt} \%$ was suggested by Head and Wilson [1986] as being representative of the possible amount of gas that could accumulate on any terrestrial planet, and this is used as an upper limit here, but is the subject of further discussion below.

\section{Size of Gas-Filled Region}

The high Venusian atmospheric pressure can have a significant effect on the density structure of growing volcanoes and so on the ascent behavior of magmas, determining whether the magma is likely to reach the surface directly or to stall as an intrusion, possibly leading to accumulation in a shallow magma chamber. Head and Wilson [1992] show that there appear to be two possibilities: in areas of intermediate to high altitude, ascending magma encounters a zone of neutral buoyancy at some depth in the crust. The magma then stalls and will only continue its ascent if gas exsolution takes place to lower the bulk density and thus increase magma buoyancy relative to the surrounding country rock. A prolonged intrusive history may lead to formation of a shallow magma reservoir, and if dikes propagate from such a reservoir they are likely to have similar widths to dikes on Earth since the planetary gravity and the total range of depths at which neutral buoyancy zone (NBZ) reservoirs reside are similar [Head and Wilson, 1992]. However, in areas of low elevation the high atmospheric pressure has a greater inhibiting effect on volatile exsolution and on the formation of NBZs [Head and Wilson, 1992] and therefore precludes the formation of shallow magma reservoirs. Magma may therefore rise directly from the mantle partial melt zones at depths of $\sim 10$ to $20 \mathrm{~km}$, leading to wider near-surface dikes than are commonly seen on Earth. Elasticity theory [Pollard, 1987] suggests that the width factor will increase only as the square root of the depth, as a first approximation, suggesting dikes 2-3 times wider. This may have some consequence for the size of the initial gas region $r_{1}$ (since $r_{1}=w / \sin \alpha$ where $w$ is the dike half-width, see Figure 1b), though it is not immediately obvious to what extent it will be affected since dike width is not the only factor controlling the gas region radius; the solid angle subtended by the gas region, $\Omega\left(\alpha=\cos ^{-1}(1-\Omega / 2 \pi)\right.$; see Figure 1) is also important. However, we explore the possibility that the region occupied by gas may be systematically larger on Venus than on Earth, and use values of $r_{1}$ in the range 10 to $200 \mathrm{~m}$. 


\section{Atmospheric Properties}

The necessary parameters describing the Venus atmosphere (variations of pressure, density and temperature with elevation above mean planetary radius) were taken from Kliore et al. [1985]. The viscosity of the atmospheric gas was computed from the temperature taking the composition to be pure $\mathrm{CO}_{2}$ and a value of $8.8 \mathrm{~m} \mathrm{~s}^{-2}$ was adopted for the acceleration due to gravity near the Venus surface.

\section{Results}

In accordance with the above considerations, the two computer programs comprising the model were run repeatedly for all permutations of the following ranges of input parameters: excess pressure in the vent, $P_{g z}=0.01$ to $20 \mathrm{MPa}$; gas mass fraction, $n=$ 0.01 to 0.3 ; gas region radius, $r_{1}=10$ to $200 \mathrm{~m}$. Both $\mathrm{H}_{2} \mathrm{O}$ and $\mathrm{CO}_{2}$ were employed as driving gases for the eruption simulations. Additionally, explosions were modeled as occurring at a range of topographic elevations, varying from the mean planetary radius (mpr=6051.84 km [Ford and Pettengill, 1992]) up to the maximum possible altitude $(\mathrm{mpr}+10 \mathrm{~km})$. Each set of figures shown is the result of modeling the motion of an ejected block of radius 1 $\mathrm{m}$ and density $2600 \mathrm{~kg} \mathrm{~m}^{-3}$.

Figure 2 presents a comparison of the ejection velocity as a function of initial gas pressure $P_{g z}$, and gas/caprock mass ratio $n$, for various combinations of driving gas and elevation on Venus and on Earth. The solid curves show the results of employing initial gas temperature of $1200 \mathrm{~K}$ (i.e., approximately magmatic temperature) in the model, whereas the dashed curves represent an initial gas temperature of $1000 \mathrm{~K}$ (allowing for the fact that the gas may have cooled somewhat during the accumulation period). In the case of magmatic gases being involved in driving the explosion, it is not anticipated that the temperature will drop significantly during accumulation, as they will be insulated to some extent by the overlying caprock. However, if external volatiles are involved, which is more likely on Earth, gas temperatures may be significantly lower, since the gas would have had to be heated up from much lower temperatures. As can be seen, the effect of advocating a lower initial gas temperature is to reduce the ejection velocity attained, which is a result of less energy being available to drive the gas expansion.

It is also apparent from Figure 2 that the ejection velocities obtained for Venus are systematically significantly lower than for the Earth. Taking a gas content of 0.10 and an initial gas pressure of $10 \mathrm{MPa}$, it can be seen that $u_{0}=95 \mathrm{~m} \mathrm{~s}^{-1}\left(\mathrm{H}_{2} \mathrm{O}\right)$ and $38 \mathrm{~m} \mathrm{~s}^{-1}$ $\left(\mathrm{CO}_{2}\right)$ on Venus, compared with $440 \mathrm{~m} \mathrm{~s}^{-1}$ and $275 \mathrm{~m} \mathrm{~s}^{-1}$, respectively, on Earth. This difference in velocity is due to the reduction of gas expansion by the oppressive atmospheric pressure environment of Venus.

It is also evident that the ejection velocity for any one set of initial parameters (gas mass fraction, initial gas pressure, choice of volatile species) is significantly greater for higher vent elevations. On Venus, for $n=0.10$ and $P_{g z}=10 \mathrm{MPa}$, an increase in ejection velocity of several tens of $\mathrm{m} \mathrm{s}^{-1}$ results from the decrease in atmospheric pressure from $\sim 10 \mathrm{MPa}$ to $5 \mathrm{MPa}$ over a $10-\mathrm{km}$ elevation difference. In terms of the explosion model, the higher atmospheric pressure at low elevations restricts the amount of gas expansion (the driving pressure term in equation (1) is much reduced) and the mass of the atmosphere to be displaced by the explosion is much greater. The accelerations and hence ejection velocities attained are therefore much smaller than they would be for the higher elevations.
In addition, the velocities attained for $\mathrm{CO}_{2}$ are significantly less than when $\mathrm{H}_{2} \mathrm{O}$ is used as the driving gas. This is a result of the greater molecular weight of $\mathrm{CO}_{2}$, which has the effect of increasing the gas density in the vent for any given gas pressure. The gas mass is thus greater than for $\mathrm{H}_{2} \mathrm{O}$, which ensures a greater caprock mass for any chosen gas mass fraction $n$. The consequent effect is a significant diminution of the accelerations of the caprock and displaced atmosphere (the denominator in equation (1) is much larger for $\mathrm{CO}_{2}$ than for $\mathrm{H}_{2} \mathrm{O}$ ), and hence much lower velocities are attained. The velocities (and hence clast ranges) produced if sulfur (likely to be in the form of $S_{2}$ ) is taken as the driving volatile are further reduced with respect to those for $\mathrm{CO}_{2}$, as a result of its even greater molecular weight (64).

The difference in clast range values between the planets is not just a consequence of the differing ejection velocities obtained for similar initial conditions, but is also the result of the differing atmospheric properties and hence the amount of retardation of the clast during flight. A comparison of the variation of projectile travel distance with initial pressure and gas mass fraction is shown in Figure 3, for various driving gases and vent elevations on Venus and Earth. In each case the models were run for a clast of radius $1 \mathrm{~m}$ and an ejection angle of $45^{\circ}$. As can be seen, the differing planetary environments act to produce very large differences in clast range, which is typically several kilometers on Earth and a few hundred meters on Venus.

Again, the effect of vent altitude and the choice of driving gas is clearly seen: for $n=0.10$ and $P_{g z}=10 \mathrm{MPa}$, Figure 3 gives, for $\mathrm{H}_{2} \mathrm{O}$ and $\mathrm{CO}_{2}$ respectively, clast ranges of 200 and $135 \mathrm{~m}$ at the mpr and 350 and $270 \mathrm{~m}$ at a vent elevation of mpr+10 km on Venus. This increase in range attained by blocks launched from explosions at higher altitudes is not merely a reflection of the increased velocities achieved by such clasts, but is also a result of the smaller retarding drag forces imposed on the clasts by the thinner atmosphere at high elevations.

A threshold value for the gas pressure is apparent in Figures 2 and 3, which is greater for lower values of $n$ and lower vent altitudes. This represents the minimum value of $P_{g z}$ required for explosive activity to occur: the explosion is suppressed by the heavy Venusian atmosphere for lower gas pressures.

Finally, Figure 4 illustrates the increase in clast range that occurs as a result of invoking a greater size of region $r_{1}$, in which gas accumulates prior to the eruption for Venus than for Earth. For greater values of $r_{1}$, larger masses of gas are involved in the explosion for any chosen value of $n$. Thus the gas expansion takes place over a greater distance, and hence $R_{0}$ is larger. For Venus (Figures $4 \mathrm{a}$ and $4 \mathrm{~b}$ ), where the clast ranges in "free" flight (i.e., subsequent to the initial expansion phase when they are still locked to the gas motion) are only of the order of $100 \mathrm{~m}$, owing to the large decelerations imposed by the retarding influence of the dense atmosphere, the additional distance contributed by the greater $R_{0}$ means that significantly larger final ranges can be obtained. For Earth (Figure 4c), the increase in clast range obtained for larger $r_{1}$ is a much lower proportion of the total range owing to the lesser degree of retardation of the clast in flight. The final velocities attained do not differ significantly for a large variation in $r_{1}$, provided $n$ is kept constant.

\section{Discussion}

The dominant factor determining the limited extent to which material may be ejected in Venusian explosions is the dense atmosphere. This restricts the exsolution and expansion of gas 
Initial Gas Pressure, $\boldsymbol{P}_{\mathbf{g z}}$ in $\mathbf{M P a}$
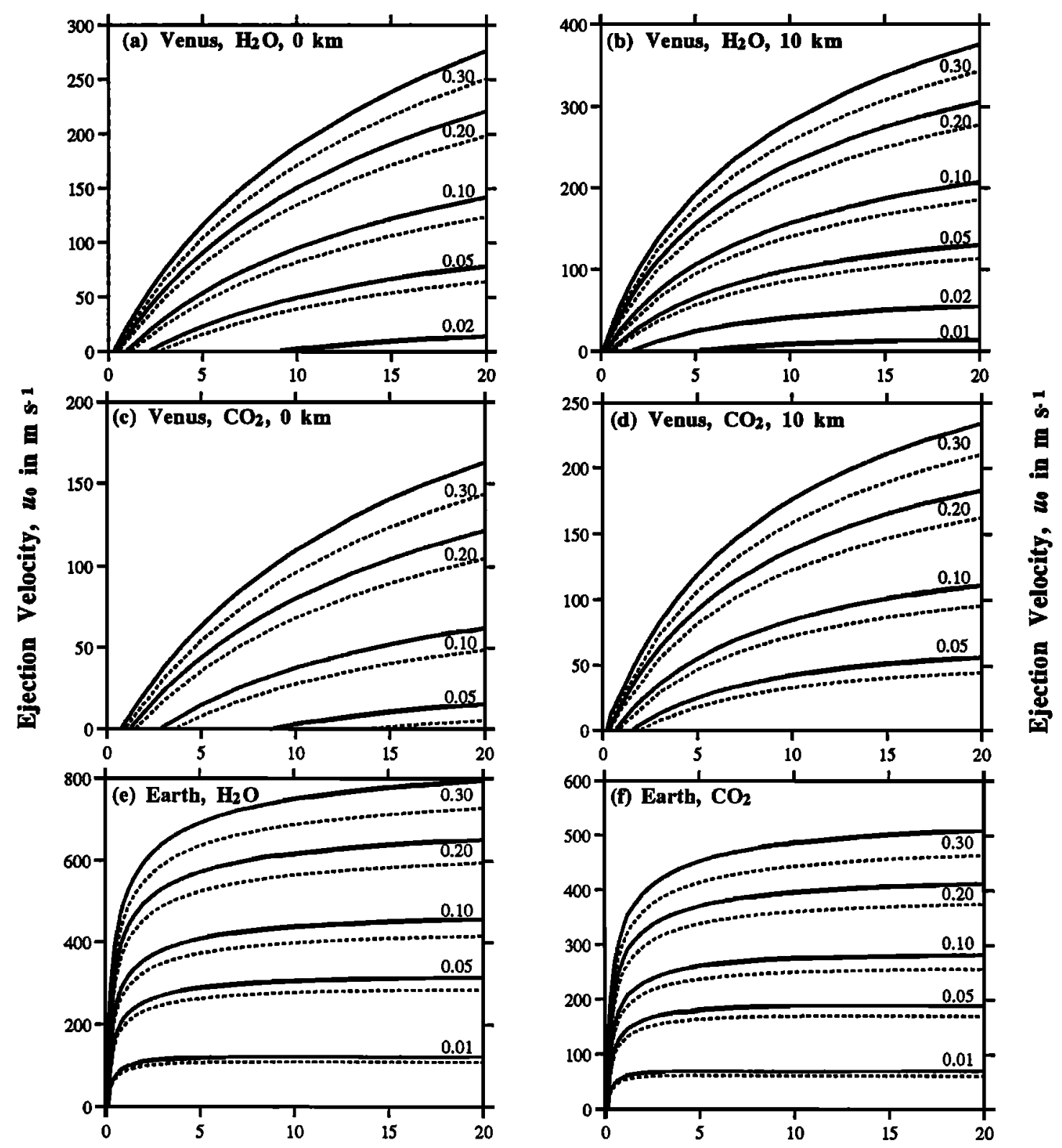

Initial Gas Pressure, $\boldsymbol{P}_{\boldsymbol{g} z}$ in $\mathrm{MPa}$

Figure 2. Ejection velocity $u_{0}$ as a function of initial excess pressure in the vent $P_{g z}$ and gas/caprock mass ratio $n$ for transient explosive eruptions. (a) Venus: driving volatile is $\mathrm{H}_{2} \mathrm{O}$, vent elevation is $0 \mathrm{~km}$ above mpr, (b) Venus: $\mathrm{H}_{2} \mathrm{O}$ at an elevation of $10 \mathrm{~km}$, (c) Venus: $\mathrm{CO}_{2}$ at $0 \mathrm{~km}$, (d) Venus: $\mathrm{CO}_{2}$ at $10 \mathrm{~km}$, (e) Earth: $\mathrm{H}_{2} \mathrm{O}$ at mean sea level (msl), and (f) Earth: $\mathrm{CO}_{2}$ at msl. Initial gas region radius $r_{1}=50 \mathrm{~m}$ for Venus, $25 \mathrm{~m}$ for Earth. Solid lines represent results of model for an initial gas temperature of $1200 \mathrm{~K}$; dashed curves represent an initial gas temperature of 1000 $\mathrm{K}$. Curves are labeled with values of the gas/rock mass ratio.

and retards the motion of clasts in flight. The question of whether there exist crustal reservoirs of volatiles that can contribute to the relatively high gas mass fractions required for Venusian explosions remains open to debate. However, it is possible to envisage sufficient gas accumulation by invoking a period of sustained sub-surface degassing prior to eruption. This must continue for a sufficient time that the lower limits on pressure and gas concentration are exceeded so that, on caprock failure, a significant explosion may occur; otherwise, no explosion takes place.

The discussion above suggested that larger dikes may occur on Venus than on Earth. The results of the modeling show that a variation in the size of the initial gas region can significantly affect pyroclast ranges on Venus, where the extra distance afforded by the larger source size may make a significant contribution to the final clast range. However, despite the possibility of wider dikes on Venus, the resulting deposits would still be very localized with respect to the Earth.

We will now consider the likely maximum ranges of fragments ejected from transient eruptions on Venus. The greatest distance is attained when each of the initial model parameters is the maximum possible [Fagents and Wilson, 1993]. Table 2 presents the modeling results for simulations at the mpr and the 
Initial Gas Pressure, $P_{z} z$ in MPa
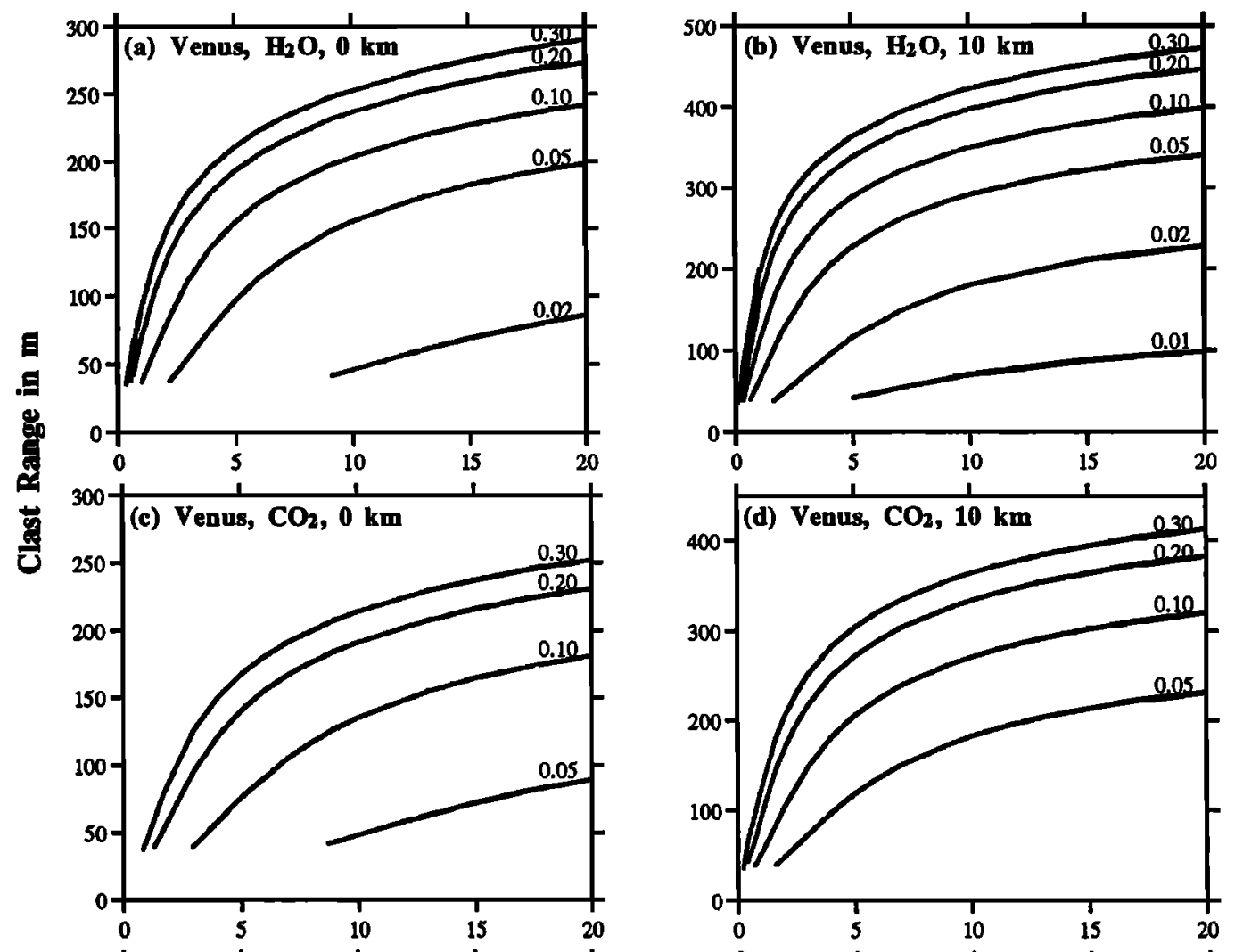

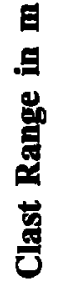
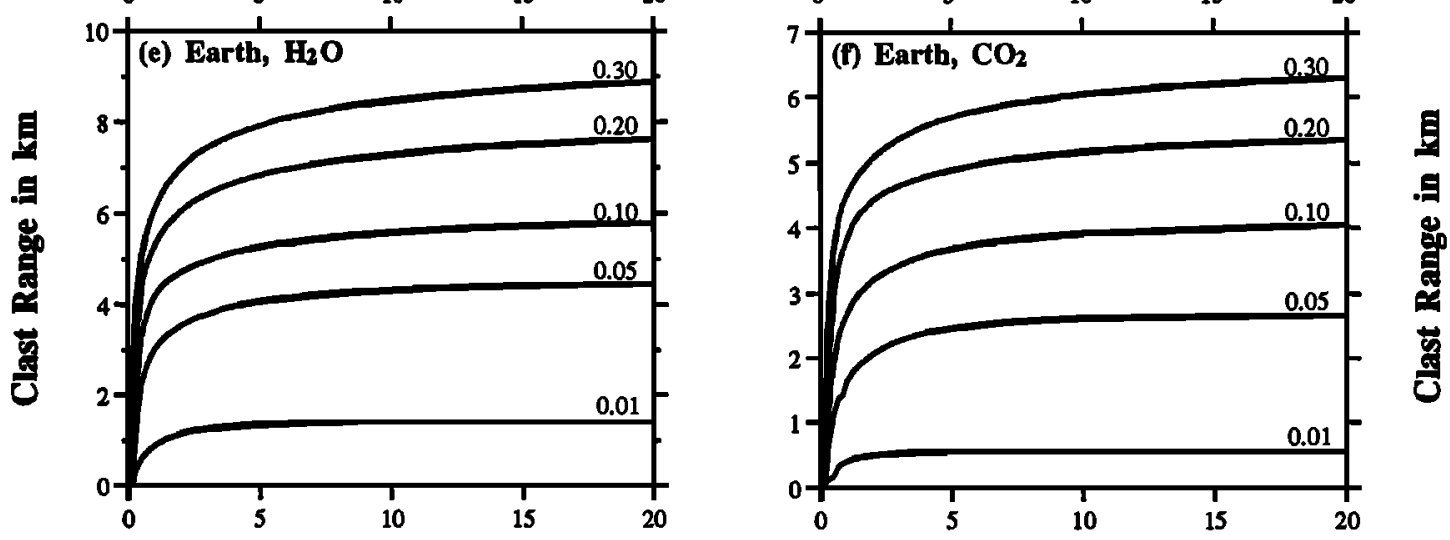

Initial Gas Pressure, $P_{z z}$ in MPa

Figure 3. Clast travel distance as a function of initial excess pressure in the vent $P_{g z}$ and gas/caprock mass ratio $n$ for transient explosive eruptions. (a) Venus: driving volatile is $\mathrm{H}_{2} \mathrm{O}$, vent elevation is $0 \mathrm{~km}$ above mpr, (b) Venus: $\mathrm{H}_{2} \mathrm{O}$ at an elevation of $10 \mathrm{~km}$, (c) Venus: $\mathrm{CO}_{2}$ at $0 \mathrm{~km}$, (d) Venus: $\mathrm{CO}_{2}$ at $10 \mathrm{~km}$, (e) Earth: $\mathrm{H}_{2} \mathrm{O}$ at msl, and (f) Earth: $\mathrm{CO}_{2}$ at msl. Initial gas region radius $r_{1}=50 \mathrm{~m}$ for Venus, $r_{1}=25 \mathrm{~m}$ for Earth, clast density is $2600 \mathrm{~kg} \mathrm{~m}^{-3}$, clast radius is $1 \mathrm{~m}$. Curves are labeled with values of the gas/rock mass ratio.

maximum planetary elevation, taking the most extreme values of block size $(5 \mathrm{~m}$, based on field measurements of the largest ejected blocks on Earth), initial pressure (20 MPa, based on considerations of the maximum possible caprock tensile strength), gas mass fraction ( 0.1 , from vent geometrical considerations), size of pressurized gas region $(200 \mathrm{~m})$, and a launch angle of $45^{\circ}$.

Taking the results for the maximum elevation and $\mathrm{H}_{2} \mathrm{O}$ as the driving gas, material is expected to be ejected to maximum distances from the vent of order $1 \mathrm{~km}$ on Venus, an order of magnitude less than the maximum likely distance calculated for the Earth [Fagents and Wilson, 1993]. More commonly, deposits from Venusian eruptions are expected to be far more localized than those on Earth.

Whereas the ejection velocities calculated by the model are in reasonable agreement with those calculated by Wilson and Head [1986], who employed the treatment of Self et al. [1979] for vulcanian explosions, their corresponding clast ranges are significantly larger than those given above. They cite a typical range of between 1 and $5 \mathrm{~km}$ for an $\mathrm{H}_{2} \mathrm{O}$ gas mass fraction of 0.1 and an initial pressure of $10 \mathrm{MPa}$, which compares with $\sim 200$ to $350 \mathrm{~m}$ (taken from Figure 3), depending on vent altitude. A maximum range of $15 \mathrm{~km}$ given by Wilson and Head [1986] does not com- 
Initial Gas Region Radius, $r_{1}$ in $\mathbf{m}$

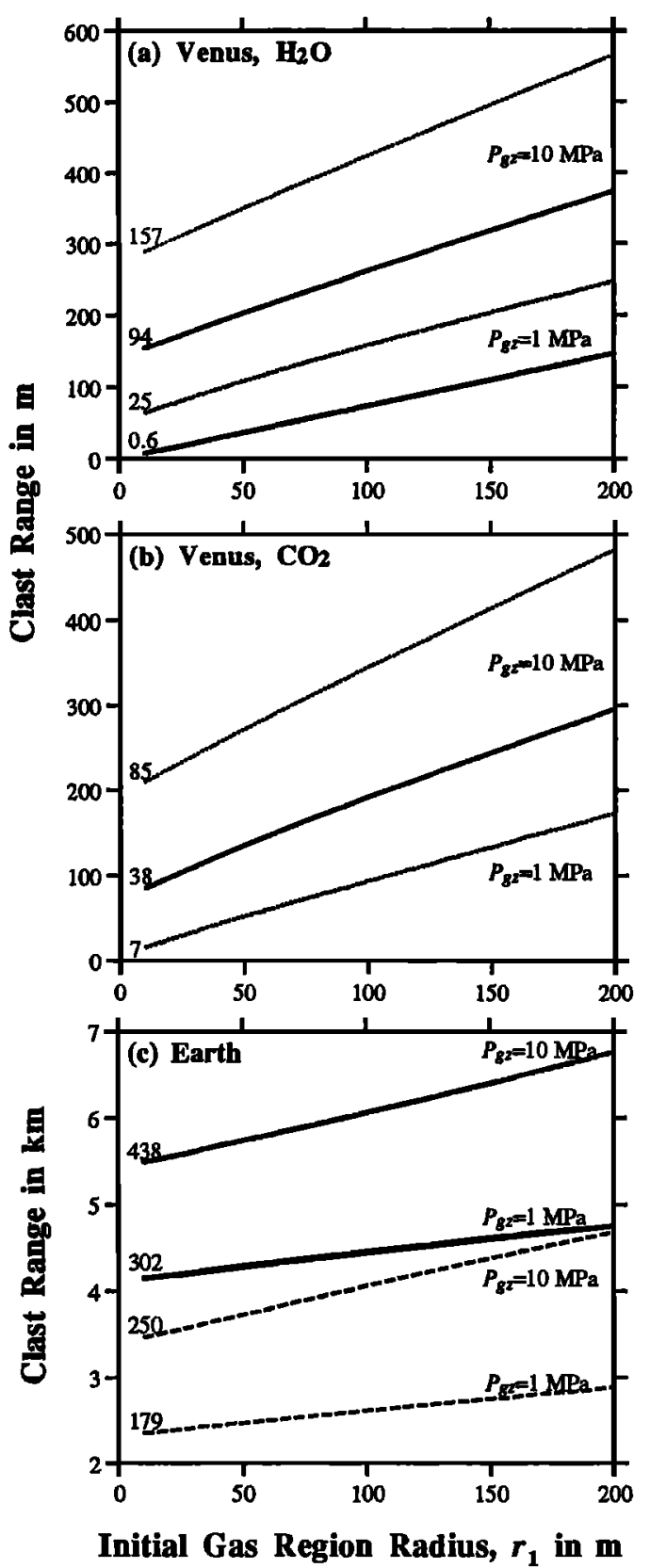

Figure 4. Clast range as a function of initial gas region radius, $r_{1}$. (a) Venus, $\mathrm{H}_{2} \mathrm{O}$ as the driving gas; (b) Venus, $\mathrm{CO}_{2}$ as the driving gas. Solid lines represent explosions at the mean planetary elevation; dotted lines represent explosions at an altitude of $10 \mathrm{~km}$. (c) Earth, explosions at mean sea level, solid lines represent $\mathrm{H}_{2} \mathrm{O}$ as the driving gas, dashed lines represent $\mathrm{CO}_{2}$. In each case, results for two initial gas pressures $\left(P_{g z}\right)$ are shown, together with the corresponding values for ejection velocity in $\mathrm{m} \mathrm{s}^{-1}$.

pare favorably with an absolute maximum of $\sim 1 \mathrm{~km}$ taken from Table 2; this discrepancy is a consequence of their having neglected the considerable drag effects of the Venusian atmosphere on even very large clasts: they calculated ranges using the classical ballistic equation for the largest clasts.

The localized nature of Venusian vulcanian deposits implies that the ejected material may build up a significant thickness in the vicinity of the vent. Repeated explosions from a central source would lead to a greater likelihood of building up an angleof-rest cone, which could then grow outwards by debris rolling or short pyroclastic flow deposition.

Alternatively, fields of closely spaced craters may be produced by impacting blocks (similar to those documented at some terrestrial volcanoes, e.g., Arenal [Fudali and Melson, 1972]), provided they have sufficient kinetic energy. It is debatable whether the deposits or crater fields may be detectable in current image data, however. The best spatial resolution of Magellan radar data $(\sim 120 \mathrm{~m} /$ pixel) may just allow deposits from the largest possible explosions to be resolved, though it must be stressed that the required combination of initial conditions $\left(n, P_{g z}, r_{1}\right.$, altitude, etc.) is unlikely. If deposits of this size cannot be identified, this confirms the improbability of occurrence of the extreme combinations of these parameters. Smaller deposits of the order of a few tens to a few hundreds of meters in diameter are unlikely to be detected other than via their effect on sub-pixel surface roughness. It is anticipated that ongoing work on the deconvolution of surface roughness, orientation, and electrical properties from the radar signal may provide a tool for the identification of such deposits in regions where explosive volcanism may have taken place.

The possible presence of pyroclastic flow deposits may increase the chance of detection of sites of transient explosions. Though they commonly (but not always) accompany vulcanian eruptions on Earth (e.g., at Ngauruhoe in 1975 [Nairm and Self, 1978] and at Galeras [Calvache and Williams, 1992]), they also accompany a range of other styles of volcanism, so careful interpretation would be required. Thornhill [1993] concluded that pyroclastic flows would occur more commonly than buoyant convecting columns in the case of high-volume flux sustained explosive eruptions (assuming that these occurred); it is not clear if this would be the case for transient eruptions. The tentative identification of a pyroclastic flow deposit [Moore et al., 1992] on plains centered about $165^{\circ} \mathrm{E}, 37^{\circ} \mathrm{S}$ implies that Magellan data are adequate for detecting larger flows, whatever their mechanism of emplacement. However, pyroclastic flows associated with terrestrial vulcanian eruptions are generally much shorter than those accompanying more violent, sustained activity owing to the limited volumes of material emitted and the lower degree of fluidization afforded by the inclusion of large amounts of nonjuvenile material at temperatures considerably lower than magmatic. Simple energy conservation arguments imply smaller flow lengths on Venus than on Earth, since the distance traveled is proportional to the square of the vent velocity [Wilson et al., 1982], which is less on Venus. However, the ability to ingest and heat dense atmospheric gas may enhance the fluidization of the flow and hence cause greater run-out distances than on Earth. Such pyroclastic flows would have to be of order $1 \mathrm{~km}$ in length to be readily discernible in current Magellan data sets.

Table 2. Comparison of the Predicted Maximum Dispersal Radii (in meters) of Material Ejected from Transient Explosions on Venus

\begin{tabular}{cccc} 
& \multicolumn{2}{c}{ VENUS } & EARTH \\
Gas & $0 \mathrm{~km}$ & $10 \mathrm{~km}$ & $\begin{array}{c}\text { Vent Altitude }= \\
\text { Vent Altitude }= \\
\text { Mean Sea Level }\end{array}$ \\
\hline $\mathrm{CO}_{\mathbf{2}}$ & 475 & 650 & 6800 \\
$\mathbf{H}_{\mathbf{2}} \mathbf{O}$ & 640 & 1010 & 10800 \\
\hline
\end{tabular}


Finally, another indication of a vulcanian deposit might be the presence of a fine ashfall deposit resulting from the convecting eruption cloud associated with such an event, extending to greater distances than the ejected blocky material. Sites for several such deposits have been proposed on Venus [Head et al., 1991, 1992; Wenrich and Greeley, 1992; Campbell, 1994; Campbell and Rogers, 1994]. Again, ashfall deposits are associated with a variety of volcanic styles, but those from vulcanian explosions are expected to be of more limited areal extent than ashfall deposits of plinian origin owing to the smaller volumes of material emitted; however, taken in context with other indications this may lead to the positive identification of deposits associated with transient eruptive activity. Indeed, a category of small volcanic cones ranging from $<2$ to $15 \mathrm{~km}$ in diameter have been identified [Guest et al., 1992], some of which have more localized ashfall deposits extending to several $\mathrm{km}$ [Bulmer, 1994].

It has been shown that the downwind width of an ashfall deposit is approximately equal to the height of the eruption cloud and that this relationship is essentially independent of the planetary atmospheric characteristics [Head and Wilson, 1986]. Cloud rise height, $h$, for discrete explosions is related by a fourth root relationship to the thermal energy available to drive convection [Morton et al., 1956] and hence to the mass of volcanic material, $M$, injected into the cloud [Settle, 1978; Wilson et al., 1978]. As a result of the differing atmospheric structures, buoyant rise is reduced on Venus: eruption cloud rise heights are expected to be around 0.6 times as large as those from the equivalent terrestrial eruptions [Esposito, 1984]. For transient explosions on Venus the relationship is

$$
h=0.98(c \Delta T F M)^{1 / 4},
$$

where $c$ is the specific heat capacity of the ash particles (essentially that of rock), $\Delta T$ is the temperature decrease experienced by the particles from vent level $(\sim 1200 \mathrm{~K})$ to their final temperature (assumed equal to that of the atmosphere), and $F$ is a factor describing efficiency of heat usage [Wilson et al., 1978].

If only $50 \%$ of the ejected material is juvenile and hence hot and able to drive convection (based on terrestrial field observations [Nairn and Self, 1978]), and of this proportion a further $50 \%$ comprises large blocky ejecta which falls essentially immediately from the column [Self et al., 1979], a value of $F=0.25$ must be assumed. It is found from equation (4) that masses of $1.8 \times 10^{8} \mathrm{~kg}$ to $6.6 \times 10^{9} \mathrm{~kg}$ are required to produce clouds rising to between 2 and $5 \mathrm{~km}$ and hence produce deposits ranging up to $5 \mathrm{~km}$ in diameter, which is consistent with the observations of Bulmer [1994]. Masses of this order can readily be ejected according to the explosion model presented above, although the larger masses require the more extreme of the possible combinations of model initial parameters (high $P_{g z}$, large $r_{1}$, low $n$ ). It is possible to obtain greater cloud heights with these masses by advocating a greater thermal efficiency factor, $F$. This would imply either a larger or a more fragmented juvenile component in the ejecta [Wilson et al., 1978]; either case would ensure that more heat would be available to drive convection. The extreme (and unrealistic) case would be when $F=1$, in which case cloud heights (and hence deposit widths) of $\sim 8 \mathrm{~km}$ might be expected. Alternatively, repeated explosions may serve to create greater deposit widths, either if they are separated by intervals of less than a few minutes [Wilson et al., 1978], causing a maintained plume to be established, or by occurring under varying wind conditions which may disperse ash along different axes. It is also worth pointing out that, while the cloud height is predominantly responsible for controlling the ashfall deposit width, the prevailing wind conditions exert a stronger control over the dimension of the deposit along the dispersal axis, so that for strong winds, ash deposits may have lengths that far exceed their widths.

It therefore appears possible that transient explosive activity provides a mechanism for distributing pyroclastic products in the Venusian environment. While not wanting to preclude the possibility of more vigorous explosive (plinian) activity, which may be required to emplace ash over greater distances (in excess of several tens of kilometers [e.g., Head et al., 1992]), the problem of the high volatile contents necessary for such activity is circumvented if vulcanian-style activity, in conjunction with the atmospheric wind régime, is able to disperse ash-sized material over distances somewhat greater than the $5 \mathrm{~km}$ theoretical maximum deposit width.

\section{Summary and Conclusions}

1. Vulcanian-style eruptions may provide a mechanism for dispersal of pyroclastic material associated with magmas having volatile contents lower than the minimum required for steady explosive eruptive activity (hawaiian or plinian) on Venus.

2. The velocity of ejection and the flight distance of clasts expelled in such explosions are sensitive to both the initial excess pressure in the driving gas and the mass ratio of the gas to solid ejecta. In addition, clast range is more sensitive to the size of the region occupied by gas prior to the explosion on Venus than on Earth.

3. Ejection velocities ranging up to a maximum of $\sim 200 \mathrm{~m} \mathrm{~s}^{-1}$ $\left(\mathrm{H}_{2} \mathrm{O}\right)$ and $\sim 100 \mathrm{~m} \mathrm{~s}^{-1}\left(\mathrm{CO}_{2}\right)$ are predicted for plausible combinations of gas content, excess pressure and gas region radius. Deposits of large, blocky ejecta are likely to be very localized, with a predicted maximum extent of $1 \mathrm{~km}$ on Venus (cf. $>10 \mathrm{~km}$ on Earth). In most cases the distribution of blocky ejecta will be below the limits of detection in Magellan SAR data.

4. Ashfall deposits or pyroclastic flows associated with transient eruptions may extend to greater distances than large blocky ejecta and therefore be identifiable in Magellan data. Eruptions analogous to vulcanian explosions on Earth could be responsible for the formation of the possible ashfall deposits having widths somewhat in excess of $5 \mathrm{~km}$ observed near small volcanic edifices on Venus. Greater dispersal is only possible from discrete explosions with a higher $(>0.25)$ thermal efficiency, or from maintained plumes arising from plinian activity or frequently repeated vulcanian explosions.

Acknowledgments. S.A.F. thanks the UK Science and Engineering Research Council for a research studentship and gratefully acknowledges the Smithsonian Institution for a Postdoctoral Research Fellowship during which the manuscript was completed. L.W. acknowledges partial support from the Royal Society through a Leverhulme Senior Research Fellowship. Both authors are grateful to Mark Bulmer, who made available his data on Venusian cones. Helpful reviews were provided by L.S. Crumpler and an anonymous reviewer.

\section{References}

Barsukov, V.L., et al., The geology and geomorphology of the Venus surface as revealed by Veneras 15 and 16, Proc. Lunar Planet. Sci. Conf. 16th, Part 2, J. Geophys. Res., 91, suppl., D378-D398, 1986.

Basaltic Volcanism Study Project, Basaltic Volcanism on the Terrestrial Planets, Pergamon, New York, 1981.

Blackburn, E.A., L. Wilson, and R.S.J. Sparks, Mechanisms and dynamics of Strombolian activity, J. Geol. Soc. London, 132, 429-440, 1976. 
Bulmer, M.H., An examination of small volcanoes in the plains of Venus with particular reference to the evolution of domes, Ph.D. thesis, Univ. of London, England, 1994.

Calvache V., M.L., and S.N. Williams, Lithic-dominated pyroclastic flows at Galeras volcano, Colombia - An unrecognized volcanic hazard, Geology, 20, 539-542, 1992.

Campbell, B.A., Merging Magellan emissivity and SAR data for analysis of Venus surface dielectric properties, Icarus, 112, 187-203, 1994.

Campbell, B.A., and P.G. Rogers, Bell Regio, Venus: Integration of remote-sensing data and terrestrial analogs for geologic analysis, $J$. Geophys. Res., 99, 21,153-21,171, 1994.

Cas, R.A.F., and J.V. Wright, Volcanic Successions, Modern and Ancient, Unwin Hyman, Boston, Mass., 1988.

Chouet, B., N. Hamisevicz, and T.R. McGetchin, Photoballistics of volcanic jet activity at Stromboli, Italy, J. Geophys. Res., 79, 4961-4976, 1974.

Decker, R.W., and D. Hadikusumo, Results of the 1960 expedition to Krakatau, J. Geophys. Res., 66, 3497-3511, 1961.

Esposito, L.W., Sulfur dioxide: Episodic injection shows evidence for active Venus volcanism, Science, 223, 1072-1074, 1984.

Fagents, S.A., The analysis of some explosive volcanic processes on the Earth, Venus and Mars, Ph.D. thesis, Lancaster Univ., Lancaster, England, 1994.

Fagents, S.A., and L. Wilson, Explosive volcanic eruptions, VII, The ranges of pyroclasts ejected in transient volcanic explosions, Geophys. J. Int., 113, 359-370, 1993.

Ford, P.G., and G.H. Pettengill, Venus topography and kilometer-scale slopes, J. Geophys. Res., 97, 13,103-13,114, 1992.

Fudali, R.F., and W.G. Melson, Ejecta velocities, magma chamber pressure and kinetic energy associated with the 1968 eruption of Arenal volcano, Bull. Volcanol., 35, 383-401, 1972.

Garvin, J.B., J.W. Head, and L. Wilson, Magma vesiculation and pyroclastic volcanism on Venus, Icarus, 52, 365-372, 1982.

Goettel, K.A., J.A. Shields, and D.A. Decker, Density constraints on the composition of Venus, Proc. Lunar Planet. Sci. Conf. 12th, 15071516, 1981.

Gorshkov, G.S., Gigantic eruption of the volcano Bezymianny, Bull. Volcanol., 20, 77-109, 1959.

Gorshkov, G.S., and G.E. Bogoyavlenskaya, Bezymyanny and its Eruption 1955-1963 (in Russian), Akad. Nauk SSSR, Moscow, 1965.

Guest, J.E., M.H. Bulmer, J. Aubele, K. Beratan, R. Greeley, J.W. Head, G. Michaels, C. Weitz, and C. Wiles, Small volcanic edifices and volcanism in the plains of Venus, J. Geophys. Res., 97, 15,949-15,966, 1992.

Head, J.W., and L. Wilson, Volcanic processes and landforms on Venus: Theory, predictions and observations, J. Geophys. Res., 91, 94079446, 1986.

Head, J.W., and L. Wilson, Magma reservoirs and neutral buoyancy zones on Venus: Implications for the formation and evolution of volcanic landforms, J. Geophys. Res., 97, 3877-3903, 1992.

Head, J.W., D.B. Campbell, C. Elachi, J.E. Guest, D.P. McKenzie, R.S. Saunders, G.G. Schaber, and G. Schubert, Venus volcanism: Initial analysis from Magellan data, Science, 252, 276-288, 1991.

Head, J.W., L.S. Crumpler, J.C. Aubele, J.E. Guest, and R.S. Saunders, Venus volcanism: Classification of volcanic features and structures, associations, and global distribution from Magellan data, J. Geophys. Res., 97, 13,153-13,198, 1992.

Hédervári, P., Volcanophysical investigations on the energetics of the Minoan eruption of Volcano Santorin, Bull. Volcanol., 32, 439-461, 1968.

Hoerner, S.F., Fluid-Dynamic Drag, S.F. Hoerner, New York, 1965.

Ivanov, M.A., Explosive volcanism on Venus? (abstract), Lunar Planet. Sci. Conf., XXIII, 577-578, 1992

Jaupart, C., and S. Vergniolle, The generation and collapse of a foam layer at the roof of a basaltic magma chamber, J. Fluid Mech., 203, 347-380, 1989.

Kienle, J., P.R. Kyle, S. Self, R.J. Motyka, and V. Lorenz, Ukinrek Maars, Alaska, I, April 1977 eruption sequence, petrology and tectonic setting, J. Volcanol. Geotherm. Res., 7, 11-37, 1980.

Kliore, A.J., V.I. Moroz, and G.M. Kesting, The Venus International Reference Atmosphere, COSPAR Rep. JPL-D-2216, Adv. Space Res., $5,1985$.

Livshitts, L.D., and L.G. Bolkhovitinov, Weak shock waves in the eruption column, Nature, 267, 420-421, 1977.

Matuzawa, T., Gasdruck bei einigen vulkanischen Ausbruchen in Japan, Bull. Earthquake Res. Inst. Univ. Tokyo, 11, 347-349, 1933.
McBirney, A.R., Factors governing the intensity of explosive andesitic eruptions, Bull. Volcanol., 37, 443-453, 1973.

McKenzie, D., P.G. Ford, F. Liu, and G.H. Pettengill, Pancakelike domes on Venus, J. Geophys. Res., 97, 15,967-15,976, 1992.

Mellors, R.A., R.B. Waitt, and D.A. Swanson, Generation of pyroclastic flows and surges by hot-rock avalanches from the dome of Mount St. Helens volcano, USA, Bull. Volcanol., 50, 14-25, 1988.

Melson, W.G., and R. Saenz, Volume, energy and cyclicity of eruptions of Arenal volcano, Costa Rica, Bull. Volcanol., 37, 416-437, 1973.

Minakami, T., On explosive activities of andesitic volcanoes and their forerunning phenomena, Bull. Volcanol., 10, 59-87, 1950.

Moore, H.J., J.J. Plaut, P.M. Schenk, and J.W. Head, An unusual volcano on Venus, J. Geophys. Res., 97, 13,479-13,494, 1992.

Morton, B.R., G. Taylor, and J.S. Turner, Turbulent gravitational convection from maintained and instantaneous sources, Proc. R. Soc. London A, 234, 1-23, 1956.

Nairn, I.A., Atmospheric shock waves and condensation clouds from Ngauruhoe explosive eruptions, Nature, 259, 190-192, 1976.

Nairn, I.A., and S. Self, Explosive eruptions and pyroclastic avalanches from Ngauruhoe in February 1975, J. Volcanol. Geotherm. Res., 3, 39 $60,1978$.

Nikolaeva, O.V., Geochemistry of the Venera 8 material demonstrates the presence of continental crust on Venus, Earth, Moon and Planets, 50/51, 329-341, 1990.

Pavri, B., J.W. Head, K.B. Klose, and L. Wilson, Steep-sided domes on Venus: Characteristics, geologic setting, and eruption conditions from Magellan data, J. Geophys. Res., 97, 13,445-13,478, 1992.

Pollard, D.D., Elementary fracture mechanics applied to the structural interpretation of dykes, in Mafic Dyke Swarms, edited by H.C. Halls and W.F. Fahrig, Geol. Soc. Can. Spec. Pap., 34, 5-24, 1987.

Ripepe, M., M. Rossi, and G. Saccorotti, Image processing of explosive activity at Stromboli, J. Volcanol. Geotherm. Res., 54, 335-351, 1993.

Sakimoto, S.E.H., and M.T. Zuber, Venus pancake dome formation: Morphologic effects of a cooling-induced variable viscosity during emplacement (abstract), Lunar Planet. Sci. Conf., XXIV, 1233-1234, 1993.

Sato, H., T. Fujii, and S. Nakada, Crumbling of dacite dome lava and generation of pyroclastic flows at Unzen volcano, Nature, 360, 664666, 1992.

Self, S., L. Wilson, and I.A. Nairn, Vulcanian eruption mechanisms, Nature, 277, 440-443, 1979.

Self, S., J. Kienle, and J.-P. Huot, Ukinrek Maars, Alaska, II, Deposits and formation of the 1977 craters, J. Volcanol. Geotherm. Res., 7, 39$65,1980$.

Settle, M., Volcanic eruption clouds and the thermal power output of explosive eruptions, J. Volcanol. Geotherm. Res., 3, 309-324, 1978.

Sheridan, M.F., and K.H. Wohletz, Hydrovolcanic explosions: The systematics of water-pyroclast equilibration, Science, 212, 1387-1389, 1981.

Sheridan, M.F., and K.H. Wohletz, Hydrovolcanism: Basic considerations and review, J. Volcanol. Geotherm. Res., 17, 1-29, 1983.

Sparks, R.S.J., The dynamics of bubble formation and growth in magmas: A review and analysis, J. Volcanol. Geotherm. Res., 23, 147-188, 1978.

Steinberg, G.S., On the determination of the energy and depth of volcanic explosions, Bull. Volcanol., 40, 1-5, 1977.

Steinberg, G.S., and J.I. Babenko, Experimental velocity and density determination of volcanic gases during eruption, $J$. Volcanol. Geotherm. Res., 3, 89-98, 1978.

Steinberg, G.S., and A.S. Steinberg, On possible causes of volcanic tremor, J. Geophys. Res., 80, 1600-1604, 1975.

Sugita, S., and T. Matsui, Are plinian type eruptions possible on Venus? (abstract), Lunar Planet. Sci. Conf., XXIV, 1375-1376, 1993.

Surkov, Yu. A., F.F. Kirnozov, V.N. Glazov, A.G. Dunchenko, and L.P. Tatsil, The content of natural radioactive elements in Venusian rock as determined by Venera 9 and Venera 10, Kosmich. Issled., 14, 704-709, 1976.

Surkov, Yu. A., F.F. Kirnozov, V.N. Glazov, and G.A. Fedoseyev, Investigations of venusian gamma-radiation by Venera 9 and Venera 10, COSPAR Space Res., 17, 659-662, 1977.

Surkov, Yu .A., V.L. Barsukov, L.P. Moskalyeva, V.P. Kharyukova, and A.L. Kemurdzhian, New data on the composition, structure and properties of Venus rock obtained by Venera 13 and 14, Proc. Lunar Planet. Sci. Conf. 14th, Part 2, J. Geophys. Res., 89, suppl., B393B402, 1984.

Surkov, Yu. A., F.F. Kirnozov, V.N. Glazov, A.G. Dunchenko, L.P. Tatsy, and O.P. Sobornov, Uranium, thorium and potassium in the 
Venusian rocks at the landing sites of Vega 1 and 2, Proc. Lunar Planet. Sci. Conf. 17th, Part 2, J. Geophys. Res., 92, suppl., E537E540, 1987.

Tait, S.R., C. Jaupart, and S. Vergniolle, Pressure, gas content and eruptive periodicity of a shallow crystallizing magma chamber, Earth Planet. Sci. Lett., 92, 107-123, 1989.

Thornhill, G.D., Theoretical modeling of eruption plumes on Venus, $J$. Geophys. Res., 98, 9107-9111, 1993.

Touloukian, Y.S., W.R. Judd, and R.F. Roy, Physical Properties of Rocks and Minerals, Data Ser. on Mater. Properties, vol. 1-2, McGraw-Hill, New York, 1981.

Turcotte, D.L., H. Ockendon, J.R. Ockendon, and S.J. Cowley, A mathematical model of vulcanian eruptions, Geophys. J. Int., 103, 211-217, 1990.

Wenrich, M.L., and R. Greeley, Investigation of Venusian pyroclastic volcanism (abstract), Lunar Planet. Sci. Conf., XXIII, 1515-1516, 1992.

Wilson, L., Explosive volcanic eruptions, II, The atmospheric trajectories of pyroclasts, Geophys. J. R. Astron. Soc., 30, 381-392, 1972.

Wilson, L., Relationships between pressure, volatile content and ejecta velocity in three types of volcanic explosion, J. Volcanol. Geotherm. Res., 8, 297-313, 1980

Wilson, L., and J.W. Head, A comparison of volcanic eruption processes on Earth, Moon, Mars, Io and Venus, Nature, 302, 663-669, 1983.

Wilson, L., J.W. Head, and P.J. Mouginis-Mark, Theoretical analysis of martian volcanic eruption mechanisms, Eur. Space Agency Spec. Publ., ESA SP-185, 107-113, 1982.

Wilson, L., R.S.J. Sparks, T.C. Huang, and N.D. Watkins, The control of volcanic column heights by eruption energetics and dynamics. $J$. Geophys. Res. , 83, 1829-1836, 1978.

Wohletz, K.H., Mechanisms of hydrovolcanic pyroclast formation: Size, scanning electron microscopy and experimental studies, in Explosive Volcanism, edited by M.F. Sheridan and F. Barberi, J. Volcanol. Geotherm. Res., 17, 31-63, 1983.

Wohletz, K.H., and M.F. Sheridan, Hydrovolcanic explosions, II, Evolution of basaltic tuff rings and tuff cones, Am. J. Sci., 283, 385413, 1983.

Wood, C.A., Venus volcanism: Environmental effects on style and landforms, NASA Tech. Memo., TM-80339, 244-246, 1979.

S.A. Fagents, Center for Earth and Planetary Studies, National Air and Space Museum, Smithsonian Institution, Washington, DC 20560. (email: sfagents@ceps.nasm.edu)

L. Wilson, Environmental Science Division, Institute of Environmental and Biological Sciences, Lancaster University, Lancaster LA1 4YQ, England. (e-mail: L.Wilson@lancaster.ac.uk)

(Received March 17, 1995; revised July 20, 1995; accepted October 17, 1995.) 